\title{
Assessing Emotional Intelligence Factors and Employees Commitment to Change
}

\author{
Norfadzilah Abd Razak $^{1}$ Faizuniah Pangil $^{2}$ \\ ${ }^{1}$ Faculty of Business Management, Universiti Teknologi Mara, Campus Puncak Alam, \\ 43200 Bandar Puncak Alam, Selangor \\ Tel: +6-016-9725927 Fax: 03- 32585000 E-mails: norfadzilah0438@ salam.uitm.edu.my \\ ${ }^{2}$ College of Business, (COB), Universiti Utara Malaysia, 06100 Sintok, Kedah \\ Tel: Tel: +6-019- 5770666 Emails: faizun@uum.edu.my
}

\begin{abstract}
This paper focused on emotional intelligence factors influenced individual commitment towards organization change. A survey was conducted among 144 administrative staffs in Universiti Utara Malaysia which is currently going through series of changes. Multiple regression analysis revealed self emotions appraisal $(\beta=$ $0.049, p>0.01)$ and use of emotions $(\beta=$ $0.068, \mathrm{p}>0.01)$ are not significant predictor of employees commitment to change. An application of the emotional intelligence helps employees set used to the new environment and ensuring the success of change. Further research is suggested for an exploring of emotional intelligence as a strategy to people managing stress at workplaces.
\end{abstract}

Keywords: Emotional intelligence, Commitment and Organizational Change

\section{Introduction}

Changes in organizations are inevitable. These changes included adapting new internal and external business environment such as changing market conditions, technology advancement, political changes, social changes, and competitive intensity [1]. Recently one of the focal concerns is the competency in managing the changes. Change which is difficult to be ignored to its unpredictability, is the main concern in the context of organization work, organization cultures, leaderships and similar issues [2]. Change challenges how things have always been done and affects the individual emotions which reflect the commitment to change. Each individual in the organizations has their own belief and values. When change occurs, existing belief, values and behavior were challenged. In managing the people's responses towards organization change, emotional intelligence has been found to be one of the competencies [3]. Emotional intelligence plays an integrated part in helping employees to implement, embrace and adapts to change in organizations [4]. But there are challenges faced in gaining commitment from employees towards the changes. However, studies on people acceptance to organization change and their commitment in the context of higher education institutions are a bit scarce. Understanding the issues of organization change in the institutions is important since there have been many academic transformational plans that require commitment from the people. Therefore, this study seeks to investigate the relationship between emotional intelligence and employees' commitment to change. 


\subsection{Literature Review}

In bridging the knowledge gap of emotional intelligence, several researchers attempted to improvise and confirm on Meyer and Salovey model of emotional intelligence. For instance, [5] adopted the model to study the relationship between leaders' emotional intelligence and employees' commitment. The study then clarifies on employees' commitment in further clarifying the two dimensions of emotional intelligence into self emotions appraisal, and use of emotions. This explains the ability to perceive emotions accurately, access and generates emotions lead the way of individual thinking [6]. According to [7] emotions are the primary determinants of behavior and achievement at workplaces. Therefore, the ways in managing emotions requires emotional intelligence in going through any situations at workplaces.

Changes lead to the new innovation and creativity which emotionally for organizational staff to embrace the change [8]. It is necessary for both the organization and employees to understand the changes occurred and meet their need [9]. Many past research have supported commitment to change is one of the most important factors to support change initiatives [10]. [11] highlighted a committed employee is the one who stays with the organization through thick and thin, attends work regularly, puts in a full day and protects company's assets, shares company goals, and so on. Because of that, the significant of change gives employees an emotional charge and has taken seriously in managing the change. In another major study, [12] found the relationship between emotional intelligent and commitment to change has been widely investigated. It would help employees to identify own abilities in social and managing the emotions at workplace. This view was supported by [6], who pointed out there was a positive relation- ship between emotional intelligence and commitment to change which contributed to the job performance. Furthermore, [13] mentioned employees who have a good level of emotional intelligence were committed to the changes. Moreover, there is a positive and statistically significant relationship between the emotional intelligence and commitment to change [14].

\subsection{Methodology}

An emotional intelligence component was prepared by adapting the procedures used by Wong and Law Emotional Intelligence Scale [5]. Adapting from the main sources, five - points Likert Scale ranging from (1) strongly disagree to (5) strongly agree were used as medium to be responded by the respondents. The initial samples consisted of 144 administrative staffs of Universiti Utara Malaysia. The respondents were selected on the basis of experienced with the organization change. All the participants were staff of College of Business (COB), College of Art and Sciences (CAS) and College of Law, Government and International Studies (COLGIS).

In the context of commitment to change, previous studies were conducted on Three Component Model introduced by [15]. In this study, it was decided that the model is the best method to be adopted in measuring the significant relationship between emotional intelligence factors and employees commitment to change. Multiple regressions were used to determine the significant relationship between the variables.

\subsection{Findings and Discussions}

The overall responded to the questionnaire was rated at $90 \%$ returned. Among the 144 administrative staffs who completed the questionnaire, 130 of the respondents provided responses to the questionnaires. The study found that 47 re- 
spondents of the study were male while 83 of the respondents were female. Most of the respondents were among 26 years old and above whom working experience was more than 2 years in Universiti Utara Malaysia (UUM).

The relationship between self emotion appraisals was tested by Pearson Coefficient against employees' commitment to change. The results indicates there was a positive and weak relationship between variables $(r=0.249)$. Meanwhile, use of emotions found there was also positive relationship with employees' commitment to change $(r=0.478)$. As compared to the multiple regression analysis the result showed as indicated in the table 1.1 below:

Table 1.1: Multiple Regression Analysis

\begin{tabular}{|l|c|c|}
\hline Variables & Beta Values & Sig. Value \\
\hline SEA & 0.049 & 0.517 \\
\hline UOE & 0.068 & 0.496 \\
\hline
\end{tabular}

Correlation is significant at the 0.01 level

The study founds there were not significant predictors of emotional factors and employees commitment to change. This means that even though the administrative staffs at UUM understand their own emotions very well, somehow it does not affect employees' commitment. This results concurs with the finding of [16] who generally found that the ability to appraise and understand one own emotion does not significantly influence the individual's overall commitment. Furthermore, according to [17] when individuals are able to use their emotion in appropriate manner, they will be more committed towards the change and consequently encourage and motivate employees to commit to their roles and duties. However, in the case of UUM, some individual who have to obey to the changes are force their emotions to accept and commit towards changes. Not at all individuals are likely to be force rather than they are willing to change.

\section{Conclusions}

This study investigated the reasons for the widespread use of emotional intelligence when changes occur in an organization. In this investigation, the aim was to assess the influences of emotional intelligence factors individual commitment towards change. The most obvious findings from this study were to understand self emotions appraisal and use of emotions in managing change. A good level of emotional intelligence enables individuals to adapt and commit to organizational changes. In addition, several implications have been identified for this study. Individual who have competences in emotional intelligence are able to give commitment during organizations changes. It influences the employees' job behavior to enhance the level of commitment towards the change. Further works need to be done to establish whether emotional intelligence facilitates people in managing stress at workplaces. However, with a small sample size, caution must be applied as the findings might not be transferable to accurate estimate of the responds. It would be interesting to access the effects of the emotional intelligence at workplaces.

\section{References}

[1] W. Weeks, J. Roberts, L. Chonko, \& E. Jones,(2004), "Organizational readiness for change, individual fear of change and sales manager performance; an empirical investigation" Journal of Personal Selling \& Sales Management, 24(1), 7.

[2] C. Erikkson,(2004), "The effect of change programs on employees' emotions", Personal Review Vol.33 No 1 (pp. 110-126)

[3] D. Goleman, And C. Cherniss, (1998), "Bringing Emotional Intelligence to Workplace, A Technical Re- 
port Issued By The Consortium For Research On Emotional Intelligence In Organizations Retrieved from www.eiconsortium.org

[4] R. D'lntino, M. Goldsby, J. Houghton, \& C. Neck, (2007). Self-Leadership: A process for entrepreneurial success, Journal of Leadership \& Organizational Studies, Vol 13 No 4, (pp: 105 120).

[5] C.Wong, and K.Law, (2002), "The effects of leader and follower emotional intelligence on performance and attitude: an exploratory study", Leadership Quarterly, Vol. 13 No. 3, (pp. 243-274)

[6] J. Meyer, T. Becker, \& C. Vandenberghe,(2004), "Employee commitment and motivation: A conceptual analysis and integrative model", Journal of Applied Psychology, Vol 89 No 6, (pp: 991-1007.)

[7] M. Zeidner, G. Matthews, \& R. Roberts, (2009). What we know about emotional intelligence: How it affects learning, work, relationships, and our mental health. Cambridge, MA: MIT Press.

[8] P. Pritchett, (2004), Culture Shift, Pritchett, Rummler-Brache, Dallas, TX

[9] A. Cork, (2005), A model for successful change management, Nursing Standard, Vol 19 No 25, (pp: 40-42)

[10] A. Armenakis, S. Harris, \& H. Feild, (1999). Paradigms in organizational change: Change agent and change target perspectives. In R. Golembiewski (Ed.), Handbook of organizational behavior (pp. 631658). New York: Marcel Dekker
[11] J. Meyer, and N. Allen, (1997), Commitment in the Workplaces: Theory, Research and Application. Thousand Oaks, CA: Sage Publications

[12]D. Goleman, And C. Cherniss, (1998), "Bringing Emotional Intelligence to Workplace, A Technical Report Issued By The Consortium For Research On Emotional Intelligence In Organizations Retrieved from www.eiconsortium.org

[13]C. Daus, \& N. Ashkanasy,(2005). The case for the ability-based model of emotional intelligence in organizational behavior. Journal of Organizational Behavior, 26, (pp.453-466)

[14]D. Bennett, (2011) "Examining the Relationship between Emotional Intelligence of Managers and Organizational Commitment of Subordinates, Retrieved from Pro Quest Dissertations and Theses database.

[15] L. Herscovitch, and J. Meyer, (2002), "Commitment to Organizational Change: Extension of a ThreeComponent Model" Journal of Applied Psychology, Vol. 87, No. 3, (pp: 474-487)

[16] I. Nikolaou, and I. Tsaousis, (2002), "Emotional intelligence in the workplace: exploring its effects on occupational stress and organizational commitment", The International Journal of Organizational Analysis, Vol. 10, pp. 327-42.

[17] S. Bedwell, (2003). Emotional Judgment Inventory. Champaign, IL: Institute for Personality and Assessment Testing, Inc. 